\title{
Crystal structure of a new modification of potassium tetrathioantimonate, $\beta-\mathrm{K}_{3} \mathrm{SbS}_{4}$
}

\author{
W. Bensch and P. Dürichen \\ Universität Frankfurt, Institut für Anorganische Chemie, Marie-Curie-Str. 11, D-60439 Frankfurt/Main, Germany
}

Received September 26, 1996, transferred to 2nd update of database ICSD in 1997, CSD-No. 402642

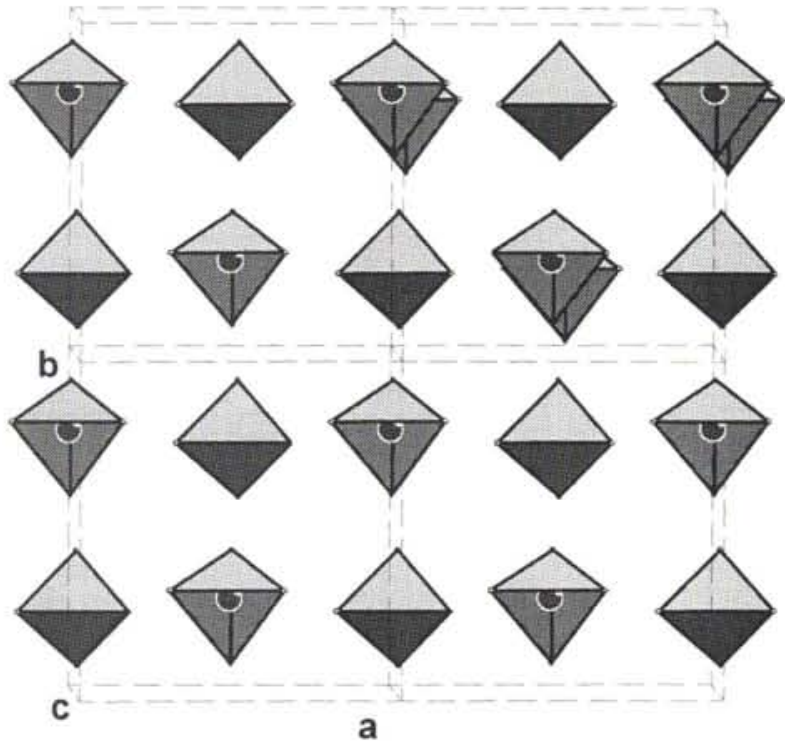

Source of material: During our investigations in the system $\mathrm{A} / \mathrm{NB} / \mathrm{Sb} / \mathrm{S}$ the compound $\mathrm{\beta}-\mathrm{K}_{3} \mathrm{SbS}_{4}$ was obtained under the following conditions. $\mathrm{K}_{2} \mathrm{~S}_{3}, \mathrm{Nb}, \mathrm{Sb}$ and $\mathrm{S}$, in a 4/1/2/8 ratio, were thoroughly mixed in a dry box. $\mathrm{K}_{2} \mathrm{~S}_{3}$ was prepared by the reaction of stoichiometric amounts of $\mathrm{K}$ and $\mathrm{S}$ in liquid ammonia under an argon atmosphere. The mixture was then loaded into a pyrexglass ampoule which was subsequently evacuated $\left(4 \times 10^{-5}\right.$ mbar) and sealed. The ampoule was heated to $623 \mathrm{~K}$ for 6 days and afterwards was cooled to roomtemperature with $3 \mathrm{~K} / \mathrm{h}$. The resulting black-red melt was washed with DMF and dried in vacuum. The product consisted of two components, red crystals of $\mathrm{K}_{6} \mathrm{Nb}_{4} \mathrm{~S}_{25}$ and white transparent crystals of $\beta-\mathrm{K}_{3} \mathrm{SbS}_{4} \cdot \beta-\mathrm{K}_{3} \mathrm{SbS}_{4}$ is hygroscopic and must be stored under dry conditions.

For X-ray crystal structure determination, a suitable crystal was mounted on a glass fiber and completely covered with glue. Despite these measure the crystal slightly decomposed during data collection. The standard reflections showed a decrease of nearly $20 \%$ intensity.

Ternary thio- and selenoantimonates (V) $\mathrm{A}_{3} \mathrm{SbQ}_{4}(\mathrm{~A}=\mathrm{Rb}, \mathrm{Cs}$, $\mathrm{NH}_{4}{ }^{+} ; \mathrm{Q}=\mathrm{S}, \mathrm{Se}$ ) crystallize either in the cubic $\left(\mathrm{NH}_{4}\right)_{3} \mathrm{SbS}_{4}$ structure type (space group $\overline{\mathbf{1 4}} \mathrm{m}$ ) or in the orthorhombic ( $\left.\mathrm{NH}_{4}\right)_{3} \mathrm{AsS}_{4}$ structure type (space group Pnma) (see refs. 1-3). The title compound crystallizes in the acentric orthorhombic space group $C m c 2_{1}$. The $\mathrm{Sb}-\mathrm{S}$ distances of $2.340 \AA$ and $2.353 \AA$ and the $\mathrm{S}-\mathrm{Sb}-\mathrm{S}$ angles of $108.9^{\circ}-109.8^{\circ}$ are in the range observed in other thioantimonates(V), and reveal that the tetrahedra are only slightly distorted. Assuming an origin shift of 1/4 in $b$ the centers of the $\mathrm{SbS}_{4}$ tetrahedra would occupy all corners and face centers of this "new" unit cell. The K1 ion is coordinated by six $\mathrm{S}$ with $\mathrm{K}-\mathrm{S}$ distances ranging from $3.173 \AA$ to $3.457 \AA$. The resulting polyhedron may be viewed as a strong distorted trigonal prism. The $\mathrm{K} 2$ center shows five short $\mathrm{K}-\mathrm{S}$ distances $(3.105 \AA-3.276 \AA)$ and two significantly longer contacts of $3.721 \AA$. Hence, the coordination number for $\mathrm{K} 2$ is $\mathbf{5 + 2}$.

$\mathrm{K}_{3} \mathrm{~S}_{4} \mathrm{Sb}$, orthorhombic, $C m c 2_{1}$ (No. 36), $a=10.712(2) \AA$, $b=11.289(2) \AA, c=7.705(2) \AA, V=931.7 \AA^{3}, Z=4, R(F)=0.053$, $R_{w}\left(F^{2}\right)=0.156$.

Table 1. Parameters used for the X-ray data collection

\begin{tabular}{ll}
\hline Crystal: & $\begin{array}{l}\text { white-transparent, irregular, } \\
\text { size } 0.14 \times 0.16 \times 0.18 \mathrm{~mm}\end{array}$ \\
Wavelength: & Mo $K_{\alpha}$ radiation $(0.71073 \AA)$ \\
$\mu:$ & $51.08 \mathrm{~cm}^{-1}$ \\
Diffractometer: & STOE AED-II \\
Scan mode: & $\omega / 2 \theta$ \\
$T_{\text {measurement: }}$ & $293 \mathrm{~K}$ \\
$2 \theta_{\max }:$ & $55^{\circ}$ \\
$\mathrm{N}(h k)_{\text {unique: }}$ & 749 \\
Criterion for $I_{0}:$ & $I_{0}>2 \sigma\left(I_{0}\right)$ \\
N(param) & 43 \\
Programs: & SHEL XS-86, SHELXL-93 \\
\hline
\end{tabular}

Table 2. Final atomic coordinates and displacement parameters (in $\AA^{2}$ )

\begin{tabular}{lllllllllll}
\hline Atom & Site & $x$ & $y$ & $z$ & $U_{11}$ & $U_{22}$ & $U_{33}$ & $U_{12}$ & $U_{13}$ & $U_{23}$ \\
\hline $\mathrm{Sb}(1)$ & $4 a$ & 0 & $0.75467(8)$ & 0.9804 & $0.0206(6)$ & $0.0146(6)$ & $0.0182(6)$ & 0 & 0 & $-0.0012(6)$ \\
$\mathrm{S}(1)$ & $4 a$ & 0 & $0.9091(4)$ & $0.7765(9)$ & $0.029(2)$ & $0.022(2)$ & $0.025(2)$ & 0 & 0 & $0.003(2)$ \\
$\mathrm{S}(2)$ & $8 b$ & $0.1778(4)$ & $0.7692(3)$ & $1.1556(6)$ & $0.027(2)$ & $0.028(1)$ & $0.028(2)$ & $0.003(1)$ & $-0.007(2)$ & $-0.004(2)$ \\
$\mathrm{S}(3)$ & $4 a$ & 0 & $0.5710(4)$ & $0.8361(9)$ & $0.038(3)$ & $0.018(2)$ & $0.023(2)$ & 0 & 0 & $0.004(2)$ \\
$\mathrm{K}(1)$ & $8 b$ & $0.2232(3)$ & $0.9699(3)$ & $0.489(1)$ & $0.039(1)$ & $0.034(1)$ & $0.047(2)$ & $0.014(1)$ & $0.005(3)$ & $0.005(2)$ \\
$\mathrm{K}(2)$ & $4 a$ & 0 & $0.7007(4)$ & $0.481(1)$ & $0.081(3)$ & $0.026(2)$ & $0.024(2)$ & 0 & 0 & $0.001(3)$ \\
\hline
\end{tabular}


Acknowledgment. Financial support by the Deutsche Forschungsgemeinschaft (DFG) is greatfully acknowledged.

\section{References}

1. Graf, H. A.; Schäfer, H.: Zur Strukturchemie der Alkalisalze der Tetrathiosäuren der Elemente der 5. Hauptgruppe. Z. Anorg. Allg. Chem. 425 (1976) 67-80

2. Wachhold, M.; Sheldrick, W. S.: Methanolothermale Synthese und Kri-stallstruktur von Tetraselenidoarsenaten (V) und -antimonaten (V) des Rubidiums und Cäsiums. Z. Naturforsch. 51 b (1996) 32-36.
3. Bensch, W.; Dürichen, P.: Crystal structure of rubidium tetrathioantimonate (V), Rb3 $\mathrm{SbS}_{4}$. Z. Kristallogr. 211 (1996) 636.

4. Sheldrick, G. M.: SHELXS-86, Phase Annealing in SHELX-90: Direct Methods for Large Structures. Acta Crystal logr. A46 (1990) 467-473.

5. Sheldrick, G. M.: SHELXL-93, a program for refining crystal structures. University of Göttingen, Germany 1993. 